AUSTRALIAN JOURNAL OF BASIC AND APPLIED SCIENCES

ISSN:1991-8178

EISSN: 2309-8414

DOI: 10.22587/ajbas.2017.11.13.3

Journal home page: www.ajbasweb.com

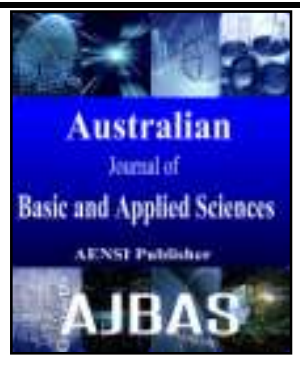

\title{
Cloud Computing Adoption by Business Organization: A Systematic Review
}

${ }^{1}$ Salem Asseed Alatresh, ${ }^{2}$ Asbi B. Ali, ${ }^{3}$ Morad Ali Ambarek

${ }^{1,2}$ College of computer Science, Management and Science University (MSU), Malaysia

Address For Correspondence:

Salem Asseed Alatresh, Management and Science University (MSU), College of computer Science, 40150 Shah Alam, Selangor, Malaysia.

\section{ARTICLE INFO}

Article history:

Received 19 August 2017

Accepted 1 November 2017

Available online 11 November 2017

Keywords:

Cloud computing, technology adoption, TAM, TOE, UTAUT, DOI, $T P B$

\begin{abstract}
A B S T R A C T
Background: Cloud computing is a new technology that can provide benefits to all stakeholders. Most of the studies attempted to find the factors that affect the adoption of this technology. However, the findings of these studies still inconclusive. In addition, the theoretical models that are used are varied. Therefore, the purpose of this paper is to review, integrate and consolidate the literature to identify the factor that affect the adoption of cloud computing by business organization. Objectives: The objectives of this paper is to identify the factors that affect the adoption of cloud computing technology by business organizations. In addition, the paper aims to provide a clear understanding about the current situation of the research in the cloud computing technology. To fulfill these objectives, a process to refine the related articles was followed. As a result, a total of 27 articles were considered related to the topic of this study. A frequency analysis was conducted on these articles. Findings: the finding showed that security, compatibility, relative advantage, complexity, privacy, ease of use and usefulness are the most important variables for the adoption of cloud computing by business organization. The Technology Acceptance Model (TAM) is the most deployed theoretical model. High percentage of the studies were conducted in emerging economies and particularly on high tech companies. Quantitative studies outperform qualitative studies. IT professional was the unit analysis of majority of the studies. Conclusion: Decision makers can benefit from this paper in the sense that the most important factors are identified so that focusing on these factors yield better adoption rate of cloud computing. Findings of previous studies are inconclusive regarding the factors that affect the cloud adoption. This study reviewed the literature and consolidated the views of previous studies. Direction of future works are given and discussed to extend the findings of this study.
\end{abstract}

\section{INTRODUCTION}

Cloud computing is considered as a new paradigm in the Information Technology (IT) that has originated in 2007(Nasir \& Niazi 2011). It is a result of innovations in Internet technologies, hardware technologies, systems management, and distributed computing (Buyya 2013). It is a dynamic technology platform that addresses a wide range of needs by providing cyber-infrastructure to maintain and extend information storage capabilities. In addition, cloud computing provides access to software and hardware without large capital investment and provides easier access to applications and services that can be realized with minimal service provider interaction (Yang, Hwang, \& Yuan, 2012). This has enabled cloud computing to develop as a technological innovation that can handle large amounts of information that are transferred and stored via electronic applications (Leymann et al. 2011).

Prior works on cloud computing attempted to find the factors that encourage users to adopt and use the technology. Several studies have used the Technology Acceptance Model (TAM) by (Davis 1989) while other

Open Access Journal

\section{Published BY AENSI Publication}

(C) 2017 AENSI Publisher All rights reserved

This work is licensed under the Creative Commons Attribution International License (CC BY).

http://creativecommons.org/licenses/by/4.0/

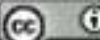


found that Models such unified theory of acceptance and use of technology (UTAUT) by (Venkatesh et al. 2003), Diffusion of Innovation (DOI) (Rogers 1995), and Technology-Organization-Environment framework (TOE) by (Tornatzky \& Fleischer 1990) have also contributed greatly to the understanding of the factors that affect and can explain the variation in the adoption of technology. Nevertheless, previous studies has no general agreement on either the factors or the theories that can be used as a reference to explain the adoption of technology.

Consequently, the purpose of this paper is to identify the factors that affect the adoption of cloud computing as well as to find the most prevailing theories and statistics related to the adoption of cloud computing by users. The paper consists of eight sections. First section has introduced the topic and highlighted the issues of this study as well as the objective. The methodology of this paper is given in second section followed by the literature review in the third section. Fourth section presents the findings followed by the discussion in fifth section. Limitation of this paper as well as direction for future work are given in sixth and seventh section respectively. Last section concludes the paper.

\section{Research Methodology:}

This study is a quantitative in nature. It reviews the existing literature to identify the factors that affect the cloud computing adoption. Key words such as adoption of cloud computing, factors affect cloud computing, cloud computing, adoption theory, and a combination of these words were used to identify the related articles that fit in the context of this study. The period of the articles was between 2011 and 2017 other articles that earlier than 2011 were not considered due to the fact that cloud computing widely spread during the year 2011. Majority of the articles were taken from emerald (91), science direct (109) and IEEE (41). A screening process was conducted to refine the articles and focus on only those that are related to topic of this paper. As a result, a total of 27 articles were considered in this study. Figure 1 shows the process of refining the articles.

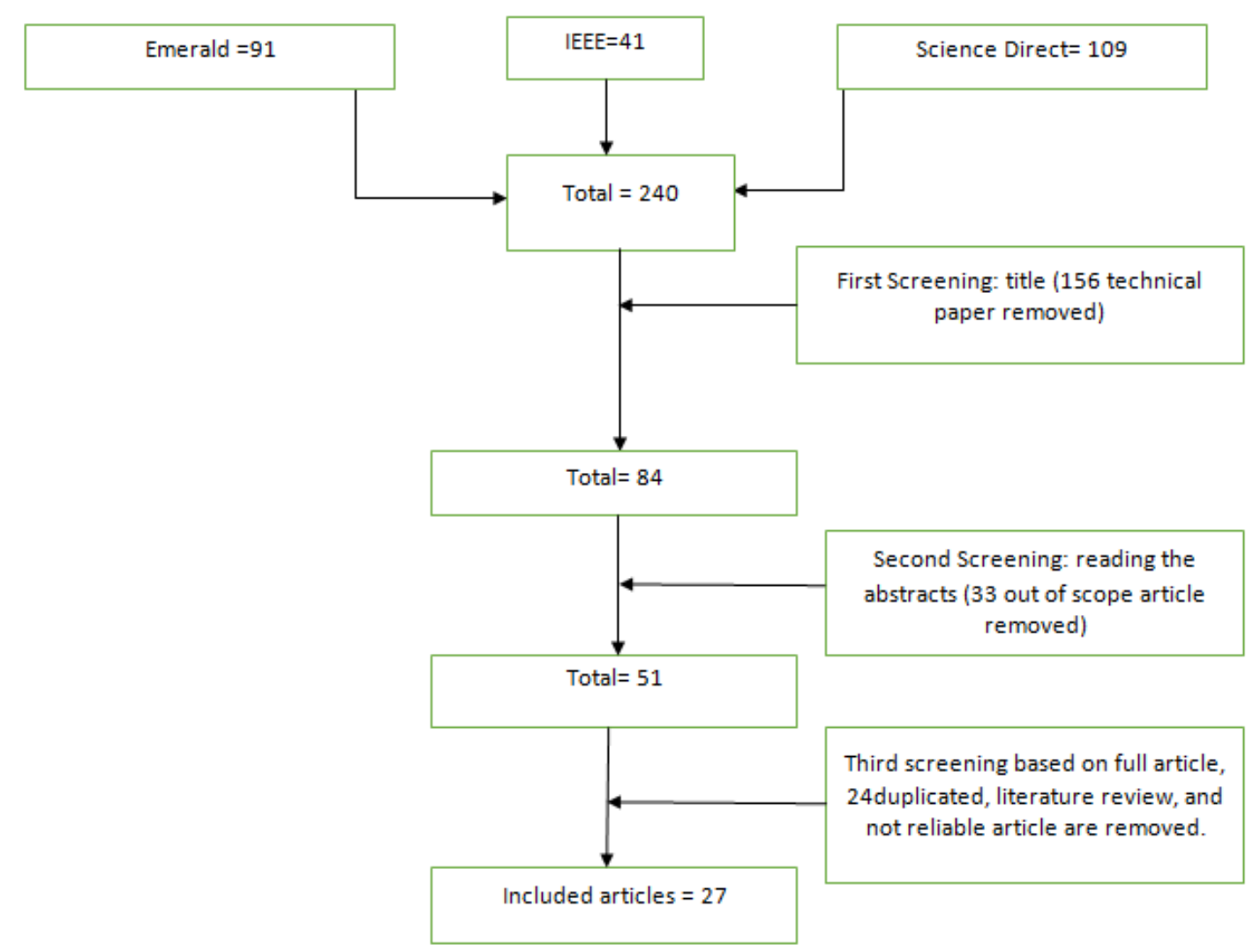

Fig. 1: Process of Selection the Related Articles

\section{Literature Review:}

This section discusses the definition, layers, and deployment of cloud computing. It also discusses the factors that affect the cloud computing adoption. 


\subsection{Cloud computing:}

Cloud computing is a newly emerged technology and it has been adopted in several industries to facilitate the sharing of resources such as software, hardware, and application. Many stakeholders can benefits from the cloud and this includes the developers, network architects and end users(Gangwar et al. 2015; Lian 2015; Flack \& Dembla 2014). The most cited definition of cloud computing is provided by the US National Institute of Standards and Technology (NIST), which refers to cloud computing as a model for enabling convenient, ondemand network access to a shared pool of configurable computing resources (networks, servers, storage, applications, and services) that can be rapidly provisioned and released with minimal management effort or service provider interaction (Mell \& Grance 2011).

Cloud computing has three main layers that includes software as a service or known as SaaS and platform as a service also known as PaaS, and infrastructure as a service known as IaaS (Han, 2013; Mavodza, 2013; Yang, Sun, Zhang, \& Wang, 2015). Each layers are design to serve specific stakeholders. For example, SaaS is designed to provide services for end users, PaaS is designed to serve developers, while IaaS is designed to serve the network architects (Prasad et al. 2014; Höfer \& Karagiannis 2011). In this paper, the focus is only on SaaS because this paper is reviewing the factors that affect the adoption by end users who are the proxies of the organization.

Several deployments can be found in cloud computing. Researchers agreed to classify cloud computing into four main deployment. First deployment is the public cloud which offer by established companies such as Microsoft while the second deployment is the private cloud where companies hold the servers on their premises. The third deployment is called hybrid cloud which a mix of private and public and lastly, the fourth deployment is the community cloud which similar to the concept of alliance between companies to share the cloud servers (Buyya, 2013; Gupta and Thakur, 2014; Ramachandran et al., 2014).

\subsection{Factors affect cloud computing adoption:}

Several studies attempted to identify the factors that affect the adoption of cloud computing by business organization. This is because using technology will improve the organizational performance of these organization Alaarj et al. 2016). As a result, variety of findings were derived and several theoretical adoption theories have been used to explain the adoption. For example, the TAM model has been used in several studies. Opitz, Langkau, Schmidt and Kolbe (2012) examined the adoption of cloud computing by IT professional in Germany using the TAM model. The findings indicate that factors such as image, job relevance and perceived usefulness have affected the acceptance and use of cloud computing by IT professional in Germany. Similarly, Gupta, Seetharaman and Raj (2013) deployed the TAM model to identify the factors that affect the cloud computing adoption by Small and Medium Enterprises (SMEs) in Malaysia using data collected from the managers of these SMEs. The finding showed that ease of use and convenience is the biggest favorable factor followed by security and privacy and then comes the cost reduction. Shin (2013) also examined the adoption of cloud computing in public sector organization using TAM and collecting data via interview as well as questionnaire. The findings emphasized on the importance of usefulness and ease of use for the adoption. In addition, the finding also indicated that availability, security, reliability, and access affect positively the perception of usefulness while the availability and access only affect the perception of ease of use. Intention to adopt cloud computing is also affected by subjective norms.

More studies have used TAM. For example, Burda and Teuteberg, (2014) utilized TAM to examine the adoption of cloud storage in Germany. The findings showed that risk and usefulness affect the adoption of cloud storage. In addition, familiarity with cloud affect the ease of use while familiarity and satisfaction affect the trust in cloud storage. In the same vein, Shin (2014) uses the TAM model to examine the adoption of cloud services in Korea. The findings indicated that availability and access affect the ease of use and usefulness. In addition, security and reliability affected the usefulness which with ease of use affect the cloud computing adoption intention. Subjective norms and intention affect the cloud computing behaviour. Wu (2011b) investigated the adoption of cloud computing in Taiwan using TAM. The finding showed that market effort, social influence, attitude, innovation, security and trust, usefulness, and ease of use affect the adoption of cloud computing.

Park and Kim (2014) also deployed the TAM model in Korean mobile cloud computing. Data collected from 1099 respondents and finding showed that perceived usefulness, connectedness, security, service and system quality, attitude, satisfaction and mobility are important factors for the adoption of mobile cloud computing in Korea. Arpaci (2016) investigated the adoption of cloud in Malaysia using the TAM and collecting data from 262 users. The findings indicated that perceived usefulness, subjective norms, and trust has a significant effect on attitude which has a significant effect on intention to use cloud computing. $\mathrm{Xu}$, Tian, $\mathrm{Xu}$, Reyes Ayala and Shen (2017) investigated the adoption of cloud computing via mobile and deployed the TAM model. The authors collected data from 419 individuals using questionnaire. The findings indicated that switching intention is affected by perceived usefulness and disconfirmation. Switching cost has negative effect on switching intention which in turn has positive effect on behaviour. 
Several studies used different adoption theory such as UTAUT, DOI and TOE. For example, the TOE framework was used in the study of Phaphoom, Wang, Samuel, Helmer, and Abrahamsson (2015) in UK who investigated the adoption of cloud among employees and decision makers. The finding indicated that there are three potential adoption inhibitor which are security, data privacy, and portability. Yang, Sun, Zhang, and Wang, (2015) investigated the readiness to use SaaS by Chinese companies. The findings indicated that organizational readiness factor (IT infrastructure, top management support), technological readiness factors (relative advantage, simplicity, computability, experienceability), and environmental readiness (competitor, and business partner pressure) have significant effect on the readiness to adopt SaaS. Morgan and Conboy (2013) also utilized TOE to investigate the adoption of cloud computing by Irish companies. The finding indicated that technological, organizational and environmental factors have significant effect on the adoption. Low et al. (2011) used the TOE to examine the adoption of cloud among high tech Taiwanese companies. The findings revealed that relative advantage, top management support, firm size, competitive pressure, and trading partner pressure characteristics have a significant effect on the adoption of cloud computing. In Ghana, Senyoet al. (2016) examined the adoption of cloud computing by IT professional and managers. TOE factors found to be significant in the context of cloud computing adoption in developing countries. Alkhateret al. (2015) examined the adoption of cloud computing among SMEs in Saudi Arabia. The findings showed that all the factors of TOE are significant predictors of the adoption.

Polyviouet al. (2015) conducted a qualitative study in six European countries and found that from technological perspective, relative advantage compatibility, and complexity are important factors. Form organizational perspective, desire for interoperability, reduction of IT management overheads, need for meeting security and environmental policies, and transparency of processes desire were identified to be positively influencing the adoption. From environmental context, bureaucracy, political matters and legal issues seem to be influencing cloud adoption in the public sector. Similarly, In Jordan, Sulaiman and Magaireah (2014) investigated the adoption of cloud computing among hospitals. An interview with five IT experts showed that adoption of cloud computing in the healthcare is affected by Technological context, which include privacy, security, and reliability. From organizational context the factors include top management support, and technology readiness. Lastly, from environmental context the factors include government policy, legal environment, and competition.

The UTAUT model was also used in the literature. Cao, Bi and Wang (2014 investigated the users' adoption of cloud computing using UTAUT model and they found that risk, innovativeness, performance expectancy, effort expectancy, and social influence affect the behavioral intention to adopt cloud storage while facilitating condition and behavioral intention affect the use behaviour in China. Bellaaj, Zekri and Albugami (2015) deployed UTAUT to find the factors that affect the cloud computing adoption in Saudi Arabia. The finding showed that performance expectancy, effort expectancy, social influence affect the intention to use cloud computing. In addition, gender and experience were found to moderate the effect among the variables.

The diffusion of Innovation (DOI) also utilized in previous studies. For example, the study of Lin and Chen (2012) interviewed IT professional to identify the factors that affect the cloud computing adoption in Taiwan. The finding showed that compatibility, business needs, security, standardization, and relative advantage are among the concerns of companies when it comes to the adoption of cloud computing. Researchers also used the theory of planned behaviour (TPB). Arpaciet al. (2015) deployed the theory to examine the use of cloud computing in educational institution in Turkey. The result indicated that security, privacy affect significantly the attitude which in turn affect the intention. Intention affected the educational use of cloud computing. Park and Ryoo (2013) deployed the two factors theory in United States (US) and found that users' switching intention to cloud services was positively affected by switching benefits whose antecedents are omnipresence of cloud services and collaboration support. The intention also was affected negatively by switching costs whose antecedents are satisfaction with incumbent IT and breath use of inclement IT. In addition, innovativeness moderated the effect of the benefit and cost on the switching intention.

Combining theories is the norm of the literature. In UTAUT, Venkatesh et al. (2003) combined eight models to come up with their UTAUT mode. Research also combined theories and model to increase the explanation of the variation in the adoption of cloud computing. Wu (2011a) combined TAM with Rough set theory to identify the factors that affect the SaaS adoption in Taiwanese high tech companies. The findings showed that items of social influence, perceived usefulness, security, and trust are the most important element that affect the adoption of SaaS. Oliveira, Thomas and Espadanal (2014) combined TAM and DOI to investigate the cloud computing adoption betweenPortugal service and manufacturing companies. The findings showed that innovation characteristic, technology, organizational, and environmental context factors have significant effect on cloud computing adoption. TAM was also combined with TOE in the study of Gangwaret al. (2015) to investigate the adoption of cloud computing among finance and manufacturing companies in India. The findings showed that technological factors (relative advantage, compatibility, and complexity), organizational factors (organizational competency, training and education, and top management support) as well as the usefulness and ease of use have significant effect on cloud computing adoption. 
TOE and human-organization-technology fit were combined in the study Lianet al. (2014) to investigate the adoption of cloud computing in Taiwanese hospital. The finding indicated that data security, perceived technical competence, cost, top manager support, and complexity are the most important factors. Further, among the proposed four dimensions the most important one is technology followed by human, organizational, and environmental factors. Shiau and Chau (2016) examined six theoretical model that are service quality (SQ), selfefficacy (SE), the motivational model (MM), TAM, the theory of reasoned action or theory of planned behavior (TRA/TPB), and DOI. The six theoretical model and the combined model showed acceptable explanatory power that can explain the adoption of cloud computing. Table 1 shows a brief summary of the review articles. It shows the authors, country, industry, sample size, statistical method, adoption theory, and unit of analysis.

Table 1: Summary of the reviewed Articles

\begin{tabular}{|c|c|c|c|c|c|c|}
\hline Author (s) & Country & Industry & Method & $\begin{array}{l}\text { Adoption } \\
\text { Theory }\end{array}$ & $\begin{array}{l}\text { Sample } \\
\text { Size }\end{array}$ & $\begin{array}{ll}\text { Unit } & \text { of } \\
\text { Analysis } & \end{array}$ \\
\hline Opitz et al.(2012) & Germany & IT Companies & Quantitative & TAM & 100 & IT professional \\
\hline Gupta et al.(2013) & Malaysia & SMEs & Quantitative & TAM & 211 & Managers \\
\hline $\begin{array}{l}\text { Park and Ryoo, } \\
(2013)\end{array}$ & USA & Education & Quantitative & $\begin{array}{l}\text { Two factors } \\
\text { theory }\end{array}$ & 188 & Students \\
\hline $\begin{array}{l}\text { Phaphoom et } \\
\text { al.(2015) }\end{array}$ & UK & Several industry & Quantitative & TOE & 352 & Managers \\
\hline $\mathrm{Wu}(2011 \mathrm{a})$ & Taiwan & High tech & Quantitative & $\begin{array}{ll}\text { TAM } & \text { and } \\
\text { Rough } & \text { Set } \\
\text { Theory } & \\
\end{array}$ & 246 & IT professional \\
\hline Lian et al. (2014) & Taiwan & Hospital & Quantitative & $\begin{array}{l}\text { TOE and } \\
\text { Human- } \\
\text { Organization- } \\
\text { Technology fit }\end{array}$ & 60 & IT professional \\
\hline Shin(2013) & Korea & Public organization & Mix method & TAM & 30 & users \\
\hline $\begin{array}{l}\text { Burda and } \\
\text { Teuteberg (2014) }\end{array}$ & Germany & Education & Quantitative & TAM & 229 & Users \\
\hline Shin(2014) & Korea & Public organization & Quantitative & TAM & 329 & Users \\
\hline $\mathrm{Wu}(2011 \mathrm{~b})$ & Taiwan & High tech & Quantitative & TAM & 42 & Managers \\
\hline $\begin{array}{l}\text { Park and Kim, } \\
(2014)\end{array}$ & Korea & $\begin{array}{l}\text { Communication } \\
\text { companies }\end{array}$ & Quantitative & TAM & 1099 & Users \\
\hline Oliveira et al.(2014) & Portugal & $\begin{array}{ll}\text { Service } & \text { and } \\
\text { manufacturing }\end{array}$ & Quantitative & TAM and DOI & 369 & Managers \\
\hline $\begin{array}{l}\text { Gangwar } \quad \text { et } \\
\text { al.(2015) }\end{array}$ & India & SMEs & Quantitative & TOE and TAM & 289 & Managers \\
\hline Lin and Chen(2012) & Taiwan & General & Qualitative & DOI & - & IT professional \\
\hline Arpaci et al.(2015) & Turkey & Education & Quantitative & TPB & 200 & Student \\
\hline Yang et al.(2015) & China & Public and private & Quantitative & TOE & 173 & Manager \\
\hline $\begin{array}{l}\text { Cao, Bi, and Wang, } \\
\text { (2014) }\end{array}$ & China & Education & Quantitative & UTAUT & 225 & Users \\
\hline $\begin{array}{ll}\text { Morgan } & \text { and } \\
\text { Conboy }(2013) & \end{array}$ & Ireland & High tech & Qualitative & TOE & - & Managers \\
\hline $\begin{array}{l}\text { Low, Chen and Wu, } \\
(2011)\end{array}$ & Taiwan & High tech & Quantitative & TOE & 111 & IT professional \\
\hline $\begin{array}{l}\text { Senyo, Effah and } \\
\text { Addae(2016) }\end{array}$ & Ghana & Several industries & Quantitative & TOE & 305 & IT professional \\
\hline $\begin{array}{l}\text { Alkhater, Wills and } \\
\text { Walters(2015) }\end{array}$ & Saudi Arabia & Several industries & Quantitative & TOE & 30 & IT professional \\
\hline $\begin{array}{lll}\begin{array}{l}\text { Bellaaj } \\
(2015)\end{array} & \text { et } \quad a l .,\end{array}$ & Saudi Arabia & SMEs & Quantitative & UTAUT & 103 & IT professional \\
\hline $\begin{array}{ll}\text { Shiau } & \text { and } \\
\text { Chau(2016) } & \end{array}$ & Taiwan & Education & Quantitative & $\begin{array}{l}\text { SQ, SE, MM, } \\
\text { TAM, } \\
\text { TRA/TPB, DOI }\end{array}$ & 487 & Student \\
\hline $\operatorname{Arpaci}(2016)$ & Malaysia & Education & Quantitative & TAM & 262 & Student \\
\hline $\begin{array}{ll}\text { Polyviou } & \text { and } \\
\text { Pouloudi(2015) } & \end{array}$ & Six Europe & Public sector & Qualitative & TOE & - & Public Manager \\
\hline $\begin{array}{l}\text { Sulaiman and } \\
\text { Magaireah(2014) }\end{array}$ & Jordan & Hospital & Qualitative & TOE & - & IT professional \\
\hline Xu et al. (2017) & China & High tech & Quantitative & TAM & 419 & Users \\
\hline
\end{tabular}

\section{Findings:}

The findings of this study are based on frequency analysis that have been conducted on the reviewed articles. First most important factors are presented followed by the most prevalent theoretical model, countries, sectors, methodological approach, sample size, and unit of analysis. 


\subsection{Factors affect the Cloud computing adoption:}

Factors that affect the adoption were extracted from each article and the result of analysis showed that the most important factor for the adoption of cloud computing is the security (17) followed compatibility (14), relative advantage (12), complexity (11), privacy, ease of use and usefulness with frequency of ten for each. Top management support (9) is one of the important factors followed by technology readiness, competitive pressure, trust, with seven frequencies for each and personal innovativeness, reliability, and cost with six frequency of each. Figure 2 shows the frequency of the factors.

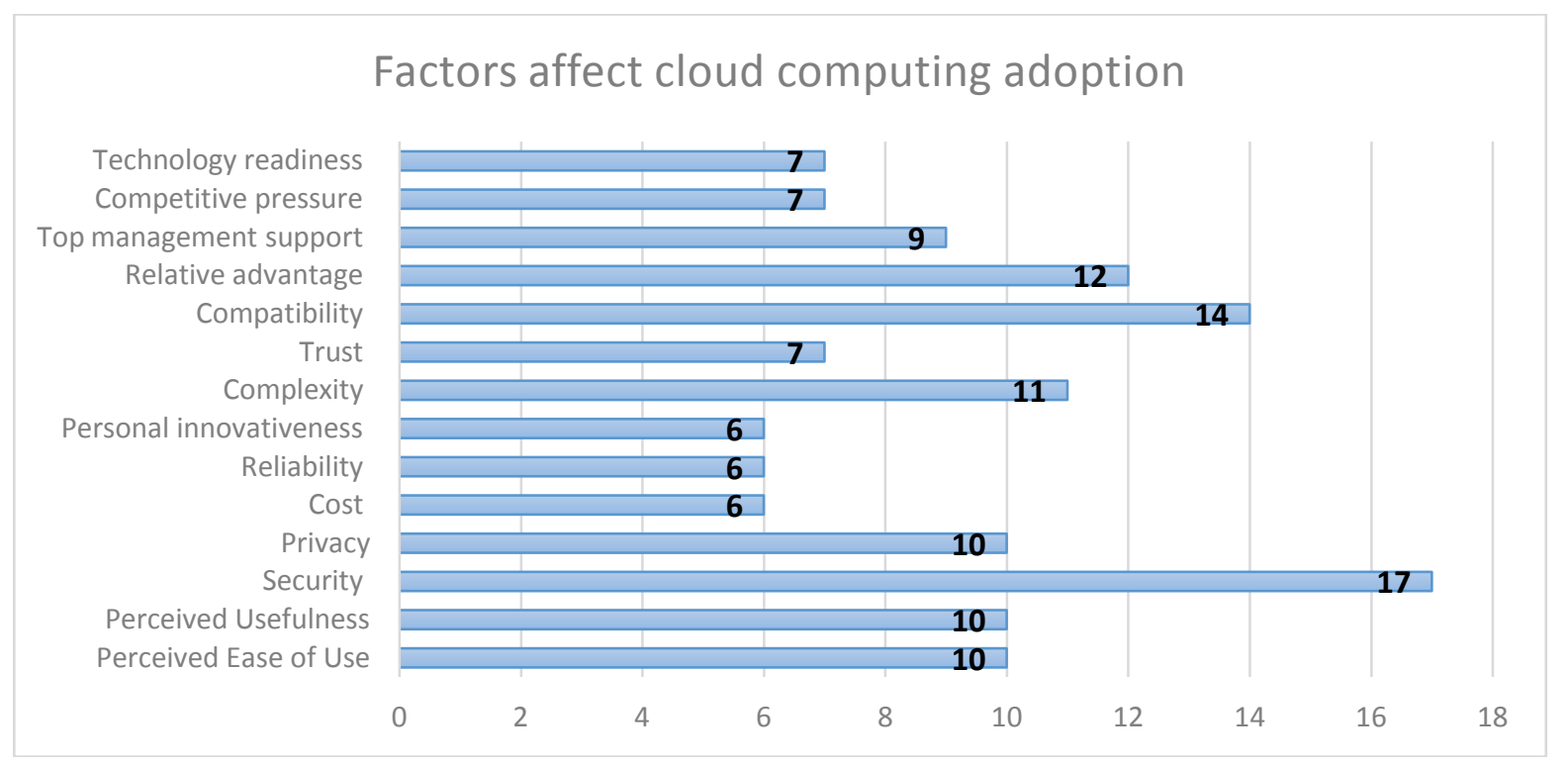

Fig. 2: Frequency of the Factors

\subsection{Theoretical model:}

The theories that have been used in previous studies are shown in Figure 3. It shows that a total of $37 \%$ of the studies have used TAM followed by $28 \%$ deployed TOE, and UTAUT (6\%), TPB (6\%), DOI (6\%).

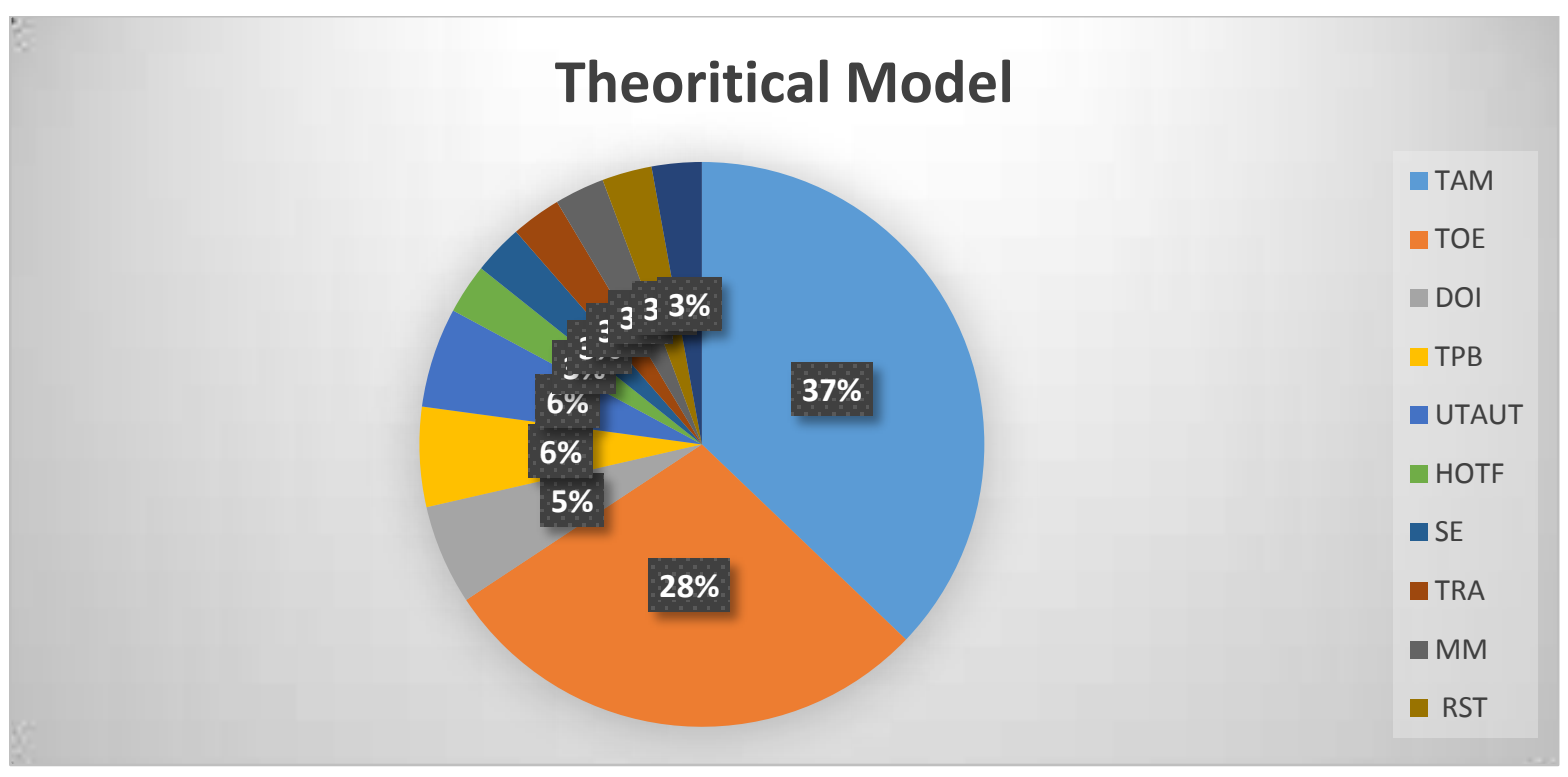

Fig. 3: Theoretical Model

In addition, some of the studies have used single theoretical model and other have combined two or more models. Figure 4 shows that $81 \%$ of the studies used single theory while $19 \%$ has combined two theories or more. 


\section{Theories}

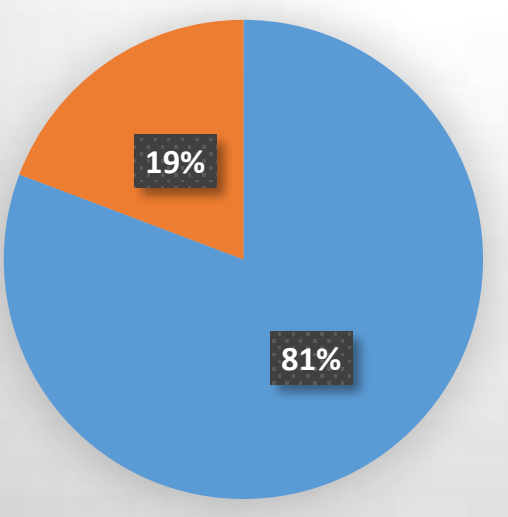

- One Theory

Combination of Theories

Fig. 4: Theories

\subsection{Countries:}

Majority of the studies were conducted in Taiwan (25\%) followed by Korea (13\%), Germany (9\%), Malaysia (9\%), Saudi Arabia (8\%). Figure 5 shows the distribution of the countries where the studies have been conducted.

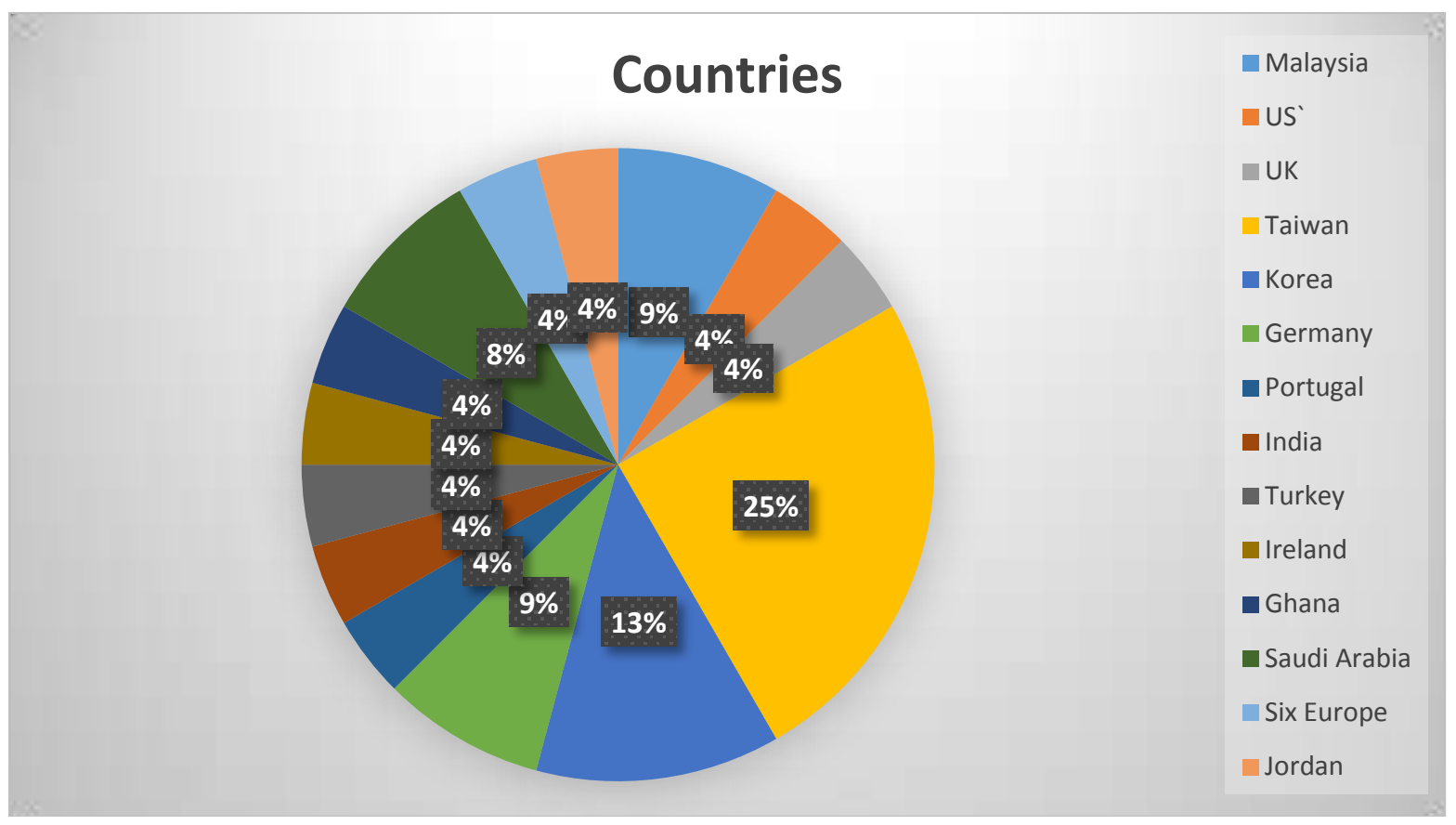

Fig. 5: Countries of the Studies

\subsection{Sectors:}

The studies have been conducted on various industries. The highest percentage among the reviewed articles was conducted on high tech $(25 \%)$ followed by education $(21 \%)$, several industry (17\%), public organization $(13 \%)$, hospital $(8 \%)$, and service and manufacturing $(4 \%)$. 


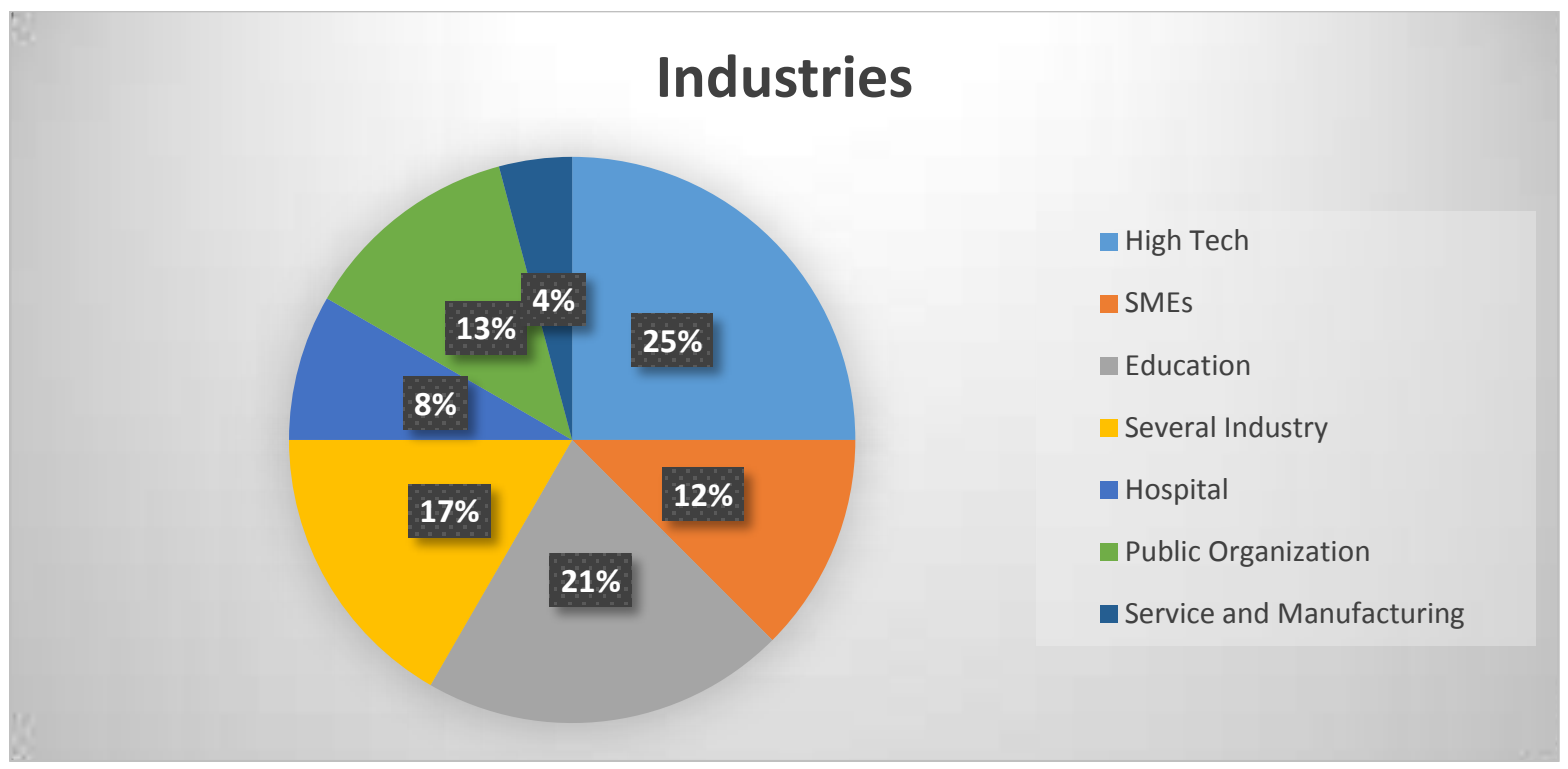

Fig. 6: Sector of the Studies

\subsection{Methodological approach:}

The quantitative studies outperformed the qualitative studies. A total of $81 \%$ of the reviewed studies are quantitative in nature followed by $15 \%$ are qualitative and $4 \%$ are mix method. Figure 7 shows the methodological approach of the studies.

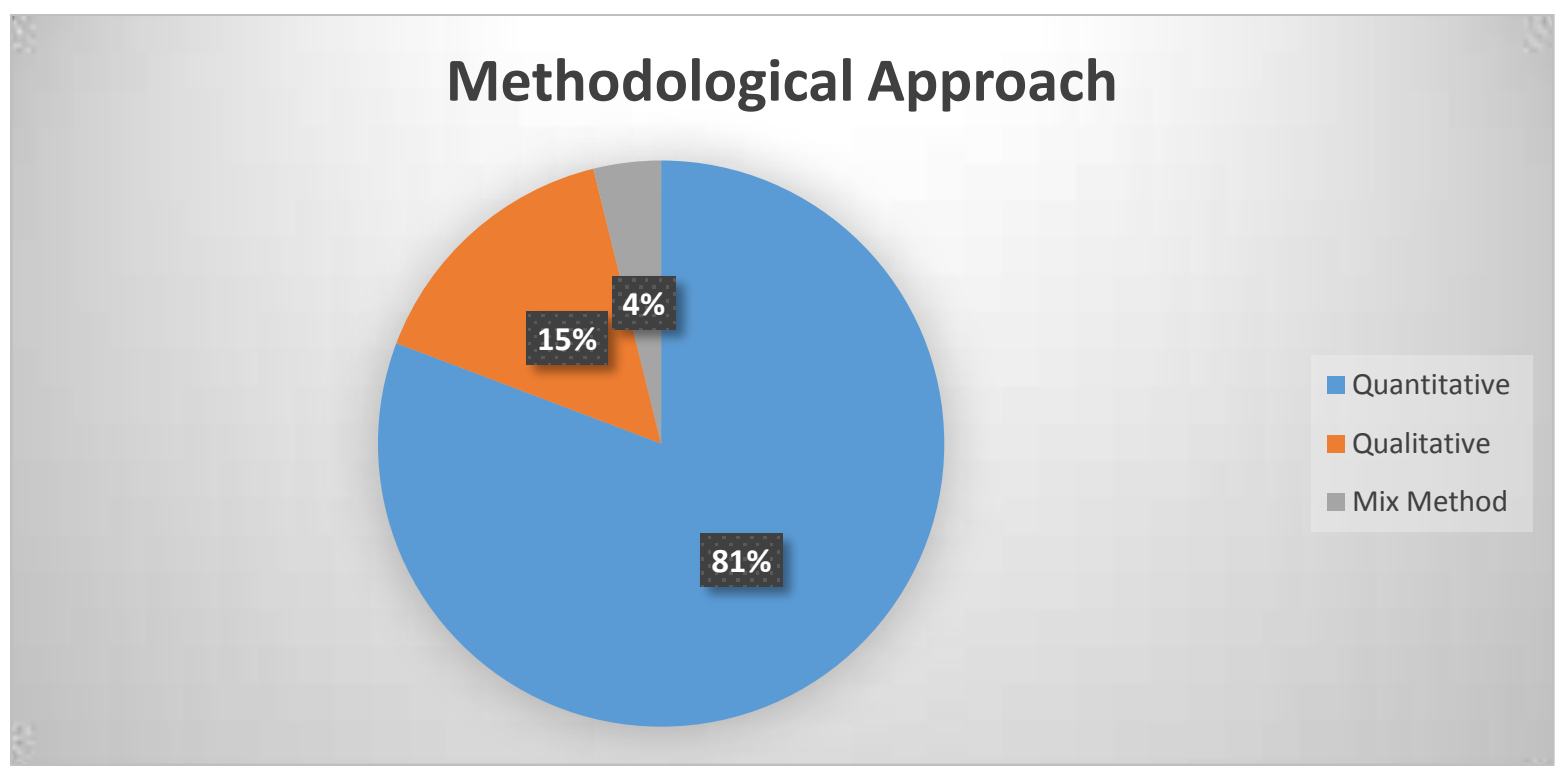

Fig. 7: Methodological Approach

\subsection{Sample size:}

The sample size of the 22 quantitative studies is presented in Figure 8. It shows that some studies have used a sample size as low as 30 respondents. The highest sample size is 1099 respondents. The mean of sample size in the studies is 247 respondents. 


\section{Sample Size}

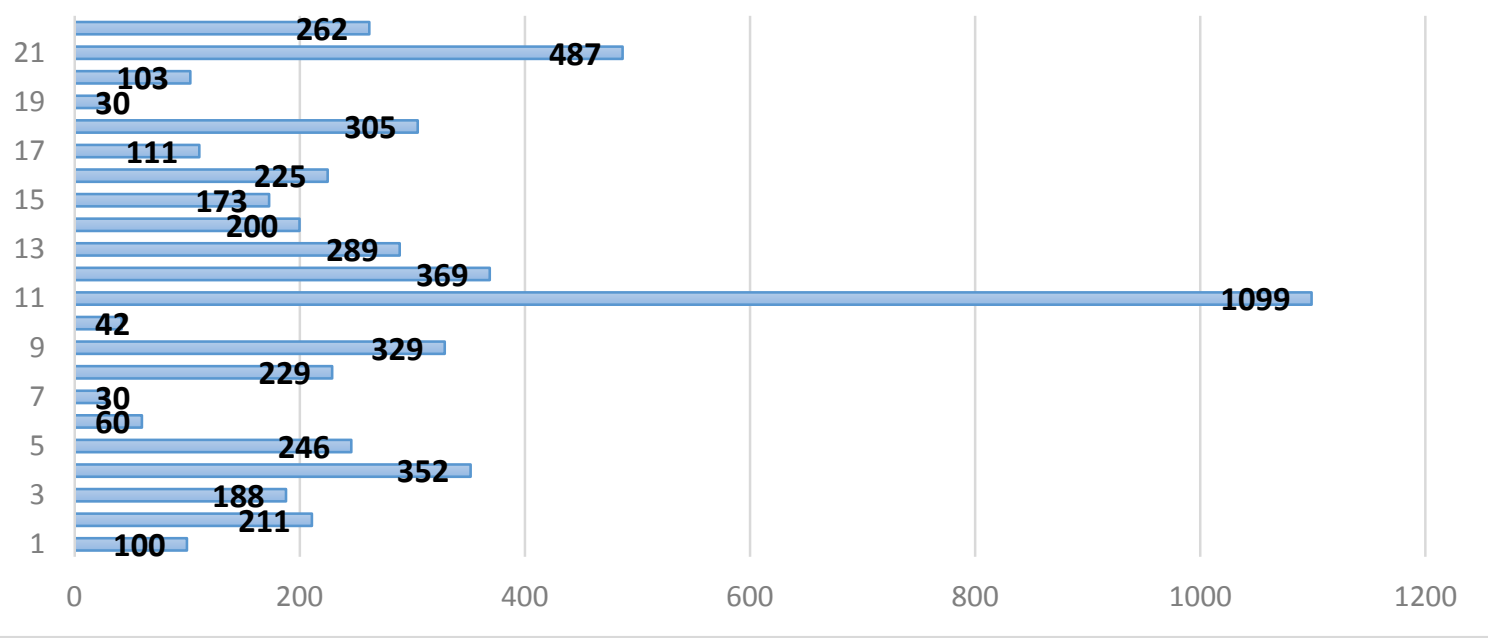

Fig. 8: Sample Size

\subsection{Unit of analysis:}

The respondents of the re viewed studies is given in Figure 9. It shows that $35 \%$ of the respondents are IT professional followed by $31 \%$ managers of companies. This is followed by $19 \%$ end users of cloud computing and $15 \%$ students.

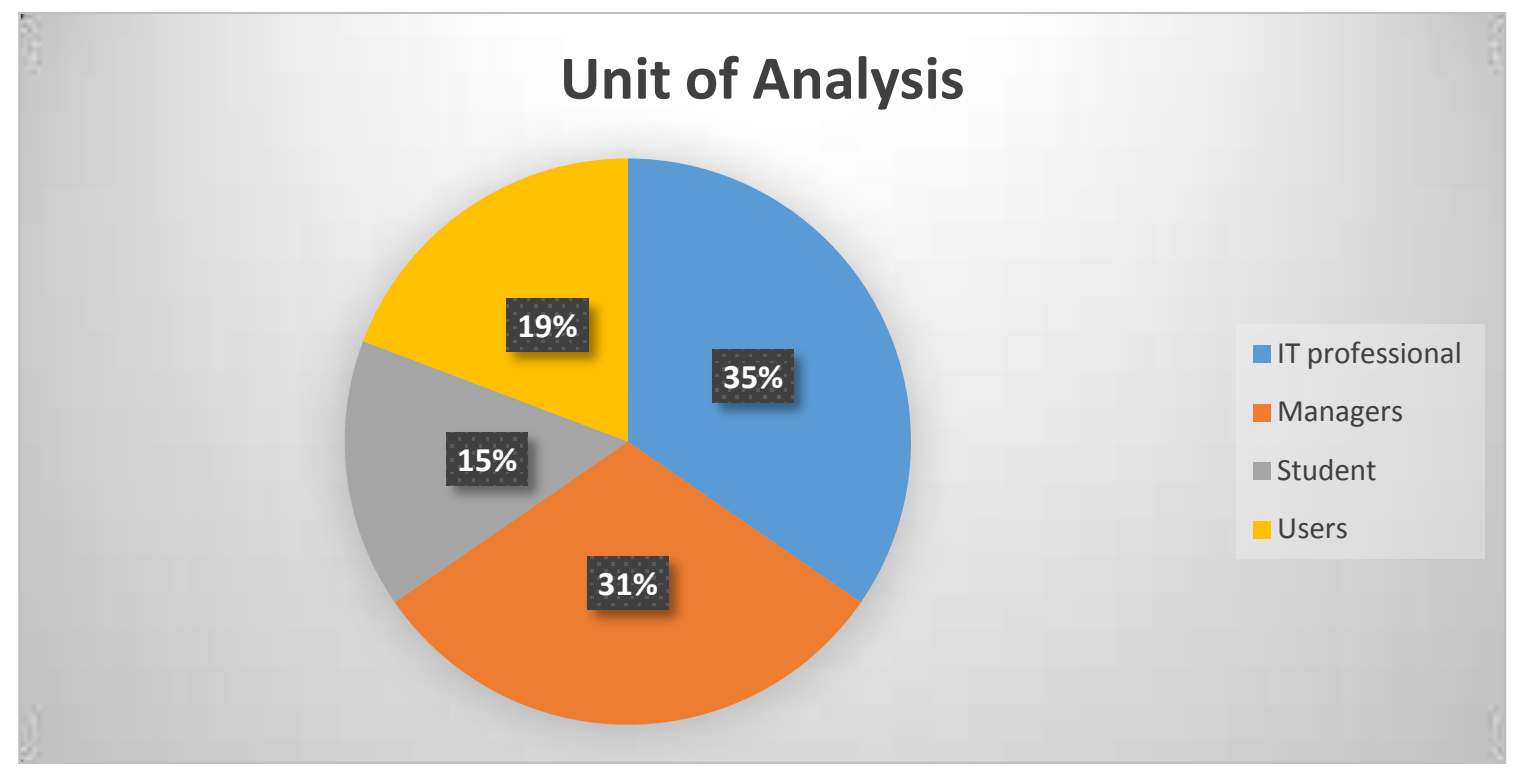

Fig. 9: Unit of Analysis

\section{Limitation and Direction for future work:}

We investigate the factors that affect the cloud computing adoption among business organization. Thus, our findings should not be generalized on other types of organizations. The findings of this study is limited to the articles that have been included in this study. Modification on the inclusion criteria of the article could result in different findings. The review articles only included empirical work between years 2011 and 2017. Expanding the period of research might lead to minor changes in the findings.

Future researchers are advised to conduct studies using variable such as security, complexity, computability, and relative advantage. This is because these variables were the most frequent in this study. They are also recommended to use theoretical model different from TAM. For example, UTAUT could better explain the variation in the cloud computing adoption. In addition, majority of the studies were conducted in developed and emerging economies such as Taiwan. Future researchers are recommended to conduct studies in developing countries especially the African countries because few of the studies conducted in this continent. High tech and 
education were attracted the attention of researchers. However, financial institution such as banks and public organization have received less attention. Future researchers are recommended to examine the adoption of cloud computing in these organizations.

Majority of the studies are quantitative in nature. Future researchers are recommended to conduct mix method or qualitative studies. They are recommended also to use focus group approach where a group of expert mediated by the researchers can discuss the factors that affect the adoption of cloud computing. Future, minority of the researches combined two or more theoretical model. Future work are advised to combine UTAUT and TOE or UTAUT and DOI to better explain the variation in the cloud computing adoption.

Sample size of some studies are limited to 30 or 60 respondents. Future work are advised to expand the sample to include more respondent. A rule of thumb to use structural equation model requires a sample size more than 200 samples. Thus, future work are recommended to increase the sample size to this level. Users are the one who will use the cloud. Thus, future researchers are recommended to consider them the unit of analysis and collect the data from them.

\section{Conclusion:}

This study was conducted to identify the factors that affect the cloud computing adoption in business organization. Consequently, the study reviewed 27 articles that are pertaining to the topic of this research. A frequency analysis was conducted to extract the factors from the reviewed articles. Decision makers can benefit from this study because it shows that security is the most important variables followed by compatibility of the existing system, relative advantage, complexity of the cloud, privacy, ease of use and usefulness. Thus focusing on these variables could better explain the adoption. The TAM model still one of the widely used theoretical model in the context of cloud computing adoption. Majority of the studies was conducted in the emerging economies such as Taiwan and high tech industry has the largest share in the studies. The quantitative approach outperformed the qualitative and the sample size considered acceptable for most of the studies. IT professional was the unit analysis of majority of the studies. Future works are recommended to include security in their new models and they are recommended to combine two or more theoretical adoption model to increase the explanatory power of their models.

\section{REFERENCES}

Alaarj, S., A.M. Zainal and U. Bustamam, 2016. Mediating Role of Trust on the Effects of Knowledge Management Capabilities on Organizational Performance. In Procedia - Social and Behavioral Sciences. The Author(s), pp: 729-738. Available at: http://dx.doi.org/10.1016/j.sbspro.2016.11.074.

Alkhater, N., G. Wills and R. Walters, 2015. Factors Influencing an Organisation's Intention to Adopt Cloud Computing in Saudi Arabia.

Arpaci, I., 2016. Understanding and predicting students' intention to use mobile cloud storage services. Computers in Human Behavior, 58: 150-157. Available at: http://dx.doi.org/10.1016/j.chb.2015.12.067.

Arpaci, I., K. Kilicer and S. Bardakci, 2015. Effects of security and privacy concerns on educational use of cloud services. Computers in Human Behavior, 45: 93-98. Available at: http://dx.doi.org/10.1016/j.chb.2014.11.075.

Bellaaj, M., I. Zekri and M. Albugami, 2015. The continued use of e-learning system: An empirical investigation using UTAUT model at the University of Tabuk. Journal of Theoretical and Applied Information Technology, 72(3): 464-474.

Burda, D and F. Teuteberg, 2014. The role of trust and risk perceptions in cloud archiving - Results from an empirical study. Journal of High Technology Management Research, 25(2): 172-187. Available at: http://dx.doi.org/10.1016/j.hitech.2014.07.008.

Buyya, R., 2013. Market-oriented cloud computing: Opportunities and challenges. In 2013 17th IEEE International Enterprise Distributed Object Computing Conference. pp: 7719.

Cao, Y., X. Bi and L. Wang, 2014. A study on user adoption of cloud storage service in china: A revised unified theory of acceptance and use of technology model. Proceedings - 2013 International Conference on Information Science and Cloud Computing Companion, ISCC-C 2013, (2012), pp: 287-293.

Davis, F.D., 1989. Perceived Usefulness, Perceived Ease of Use, and User Acceptance of Information Technology. Source: MIS Quarterly, 13(3): 319-340.

Flack, C.K. and P. Dembla, 2014. Influence of Cloud-Based Computing on User Productivity. Proceedings of the Southern Association for Information Systems Conference (SAIS 2014), Macon, GA, USA, March 21st22nd, 2014., pp: 1-7.

Gangwar, H., H. Date and R. Ramaswamy, 2015. Understanding determinants of cloud computing adoption using an integrated TAM-TOE model. Journal of Enterprise Information Management, 28(1): 107-130. Available at: http://www.emeraldinsight.com/journals.htm?issn=17410398\&volume $=26 \&$ issue $=3 \&$ articleid=17086871 \&show $=\mathrm{html} \% 5 \mathrm{Cnhttp}: / / \mathrm{www} \cdot$ emeraldinsight $. \mathrm{com} / \mathrm{doi} / \mathrm{abs} / 10$. 
1108/JEIM-08-2013-0065.

Gupta, N. and S. Thakur, 2014. The factors affecting adoption of cloud computing technology in education institutions. International Journal of Advanced Research in Computer and Communication Engineering, 3(6): 7229-7235.

Gupta, P., A. Seetharaman and J.R. Raj, 2013. The usage and adoption of cloud computing by small and medium businesses. International Journal of Information Management, 33(5): 861-874. Available at: http://dx.doi.org/10.1016/j.ijinfomgt.2013.07.001.

Han, Y., 2013. IaaS cloud computing services for libraries: cloud storage and virtual machines. OCLC Systems \& Services, 29(2): 87-100. Available at: http://www.emeraldinsight.com/10.1108/10650751311319296.

Höfer, C.N. and G. Karagiannis, 2011. Cloud computing services: Taxonomy and comparison. Journal of Internet Services and Applications, 2(2): 81-94.

Leymann, F. et al., 2011. Moving Applications To the Cloud: an Approach Based on Application Model Enrichment,

Lian, J.W., 2015. Critical factors for cloud based e-invoice service adoption in Taiwan: An empirical study. International Journal of Information Management, 35(1): 98-109. Available at: http://dx.doi.org/10.1016/j.ijinfomgt.2014.10.005.

Lian, J.W., D.C. Yen and Y.T. Wang, 2014. An exploratory study to understand the critical factors affecting the decision to adopt cloud computing in Taiwan hospital. International Journal of Information Management, 34(1): 28-36. Available at: http://dx.doi.org/10.1016/j.ijinfomgt.2013.09.004.

Lin, A. and N.-C. Chen, 2012. Cloud computing as an innovation: Perception, attitude, and adoption. International Journal of Information Management, 32: 533-540. Available at: http://dx.doi.org/10.1016/j.ijinfomgt.2012.04.001.

Low, C., Y. Chen and M. Wu, 2011. Understanding the determinants of cloud computing adoption. Industrial Management \& Data Systems, 111(7): 1006-1023. Available at: http://www.emeraldinsight.com/doi/abs/10.1108/02635571111161262.

Mavodza, J., 2013. The impact of cloud computing on the future of academic library practices and services. New Library World, 114(3/4): 132-141.

Mell, P. and T. Grance, 2011. The NIST Definition of Cloud Computing Recommendations of the National Institute of Standards and Technology. Nist Special Publication, 145, p.7. Available at: http://www.mendeley.com/research/the-nist-definition-about-cloud-computing/.

Morgan, L. and K. Conboy, 2013. Factors Affecting The Adoption Of Cloud Computing: An Exploratory Study. Ecis 2013, pp: 1-12. Available at: http://www.staff.science.uu.nl/ Vlaan107/ecis/files/ECIS2013-0710paper.pdf.

Nasir, U. and M. Niazi, 2011. Cloud computing adoption assessment model (CAAM). Profes '11, 44(0): 34-37.

Oliveira, T., M. Thomas and M. Espadanal, 2014. Assessing the determinants of cloud computing adoption: An analysis of the manufacturing and services sectors. Information \& Management, 51(5): 497-510. Available at: http://www.sciencedirect.com/science/article/pii/S0378720614000391.

Opitz, N. et al., 2012. Technology Acceptance of Cloud Computing: Empirical Evidence from German IT Departments. 2012 45th Hawaii International Conference on System Sciences, pp: 1593-1602.

Park, E. and K.J. Kim, 2014. An integrated adoption model of mobile cloud services: Exploration of key determinants and extension of technology acceptance model. Telematics and Informatics, 31(3): 376-385. Available at: http://dx.doi.org/10.1016/j.tele.2013.11.008.

Park, S.C. and S.Y. Ryoo, 2013. An empirical investigation of end-users' switching toward cloud computing: A two factor theory perspective. Computers in Human Behavior, 29(1): 160-170. Available at: http://dx.doi.org/10.1016/j.chb.2012.07.032.

Phaphoom, N. et al., 2015. A survey study on major technical barriers affecting the decision to adopt cloud services. Journal of Systems and Software, 103, pp: 167-181. Available at: http://dx.doi.org/10.1016/j.jss.2015.02.002.

Polyviou, A. and N. Pouloudi, 2015. Understanding cloud adoption decisions in the public sector. In Proceedings of the Annual Hawaii International Conference on System Sciences, pp: 2085-2094.

Prasad, A., P. Green and J. Heales, 2014. On governance structures for the cloud computing services and assessing their effectiveness. International Journal of Accounting Information Systems, 15(4): 335-356.

Ramachandran, N., P. Sivaprakasam, G. Thangamani and G. Anand, 2014. Selecting a suitable Cloud Computing technology deployment model for an academic institute. Campus-Wide Information Systems, 31(5): 319-345. Available at: http://dx.doi.org/10.1108/CWIS-11-20130062\%5Cnhttp://www.emeraldinsight.com/doi/abs/10.1108/CWIS-09-2014-0018.

Rogers, E.M., 1995. Diffusion of innovations,

Senyo, P.K., J. Effah and E. Addae, 2016. Preliminary insight into cloud computing adoption in a developing country. Journal of Enterprise Information Management, 29(4). 
Shiau, W.L. and P.Y.K. Chau, 2016. Understanding behavioral intention to use a cloud computing classroom: A multiple model comparison approach. Information and Management, 53(3): 355-365. Available at: http://dx.doi.org/10.1016/j.im.2015.10.004.

Shin, D., 2014. Beyond user experience of cloud service: Implication for value sensitive approach. Telematics and Informatics, 32(1): 33-44. Available at: http://dx.doi.org/10.1016/j.tele.2014.02.002.

Shin, D.H., 2013. User centric cloud service model in public sectors: Policy implications of cloud services. Government Information Quarterly, 30(2): 194-203. Available at: http://dx.doi.org/10.1016/j.giq.2012.06.012.

Sulaiman, H. and A.I. Magaireah, 2014. Factors affecting the adoption of integrated cloudbased e- health record in healthcare organizations: a case study of Jordan. Information Technology and Multimedia (ICIMU), 2014 International Conference on, pp: 102-107.

Tornatzky, L.G. and M. Fleischer, 1990. The processes of technological innovation. The Journal of Technology Transfer, 16(1): 45-46.

Venkatesh, V. et al., 2003. User acceptance of information technology: Toward a unified view. MIS Quarterly: Management Information Systems, 27(3): 425-478. Available at: http://www.scopus.com/inward/record.url?eid=2-s2.0-1542382496\&partnerID=tZOtx3y1.

Wu, W.-W., 2011. Mining significant factors affecting the adoption of SaaS using the rough set approach. Journal of Systems and Software, 84(3): 435-441. Available at: http://dx.doi.org/10.1016/j.jss.2010.11.890.

Wu, W.W., 2011. Developing an explorative model for SaaS adoption. Expert Systems with Applications, 38(12): 15057-15064. Available at: http://dx.doi.org/10.1016/j.eswa.2011.05.039.

$\mathrm{Xu}$, F. et al., 2017. Understanding Chinese users' switching behaviour of cloud storage services. The Electronic Library, 35(2): 214-232. Available at: http://www.emeraldinsight.com/doi/10.1108/EL-04-20160080 .

Yang, C.L., B.N. Hwang and B.J.C. Yuan, 2012. Key consideration factors of adopting cloud computing for science. CloudCom 2012 - Proceedings: 2012 4th IEEE International Conference on Cloud Computing Technology and Science, pp: 597-600.

Yang, Z. et al., 2015. Understanding SaaS adoption from the perspective of organizational users: A tripod readiness model. Computers in Human Behavior, 45: 254-264. Available at: http://dx.doi.org/10.1016/j.chb.2014.12.022. 